\title{
Parts of the Whole: When Variation is the Goal
}

\author{
Dorothy Wallace \\ Dartmouth College, dorothy.wallace@dartmouth.edu
}

Follow this and additional works at: https://digitalcommons.usf.edu/numeracy

Part of the Curriculum and Instruction Commons, Educational Methods Commons, Higher Education Administration Commons, Science and Mathematics Education Commons, and the Teacher Education and Professional Development Commons

\section{Recommended Citation}

Wallace, Dorothy. "Parts of the Whole: When Variation is the Goal." Numeracy 6, Iss. 1 (2013): Article 8. DOI: http://dx.doi.org/10.5038/1936-4660.6.1.8 


\title{
Parts of the Whole: When Variation is the Goal
}

\author{
Abstract \\ The goals of higher education are a population of extreme variability in expertise, a diffusion of \\ specialized knowledge across disciplinary boundaries, and production of strong K-12 teachers. Promoting \\ these three goals has implications at all granularities, from the pedagogy of an individual college \\ professor to the incentives and policies that shape systemic change. \\ Keywords \\ educational policy, postsecondary education, pedagogy, mathematics education, science education \\ Creative Commons License \\ (c) (i) (9) \\ This work is licensed under a Creative Commons Attribution-Noncommercial 4.0 License

\section{Cover Page Footnote} \\ Dorothy Wallace is a professor of mathematics at Dartmouth. She was 2000 New Hampshire CASE \\ Professor of the Year, and the lead PI of the seminal NSF project, Mathematics Across the Curriculum. \\ She recently finished a text in mathematical biology for first-year students, "Situated Complexity." She was \\ a charter board member of the National Numeracy Network and is now co-editor of this journal.
}

This column is available in Numeracy: https://digitalcommons.usf.edu/numeracy/vol6/iss1/art8 


\section{Parts Of The Whole A Column by $\mathrm{D}$. Wallace}

The problem of how best to improve the numeracy of a society is a thorny one, embracing the learning process of a single student but rising in scale to include the management and alteration of an entire system of education. With the issue of quantitative literacy always in mind, this column considers various aspects of the systemic workings of education, the forces acting on classrooms, teachers and students, and mechanisms of both stasis and change.

\section{When Variation is the Goal}

Many of the columns in this series have been dedicated to the problem of variation; how variation in student understanding increases (inevitably) through the K-12 years, how it affects the classroom and policy decisions, and how to manage a classroom in order to keep it in bounds. All of these discussions have treated variation as something to be minimized. In this column, we will consider situations in which high variation is an explicit goal of education.

The purposes of a college education stand as a stark contrast to those of the K-12 levels, where state and national standards propose a body of knowledge and set of skills to be demanded of every student. A few examples of mission statements from various institutions illuminate some of these purposes:

- Dartmouth College "prepares them for a lifetime of learning and of responsible leadership."

- Iona College produces "graduates recognized for their ethics, creativity, and problem solving abilities; their independent and adaptable thinking; their joy in lifelong learning; and their enduring integration of mind, body, and spirit."

- Grinnell "aims to graduate women and men who can think clearly, who can speak and write persuasively and even eloquently, who can evaluate critically both their own and others' ideas, who can acquire new knowledge, and who are prepared in life and work to use their knowledge and their abilities to serve the common good."

- Savannah College of Art and Design works "to prepare talented students for professional careers."

- Southwest Tennessee Community College aims to provide "a high quality and affordable post-secondary education that prepares them for associate degrees, future educational opportunities, and successful employment." 
Notice that only one of these specifically states what is now called a "learning objective," namely "to speak and write persuasively" (Grinnell). The rest may be summarized in a very short list: learn to think well (critical, adaptable thinking), be prepared for the job market or more education as needed, be ready to serve society well. Even when the mission statements superficially look the same, as when SCAD and STCC both desire successful employment for their graduates, they cannot possibly mean the same thing when translated to the actual education of the students.

A college that produced a population of graduates all educated to the same standard in a few important areas would be considered a dismal failure. Even if a college is specialized in comparison with a liberal arts institution, such as an engineering or music school, the core of common knowledge expected from graduates falls far short of the larger goal of a college education. Most colleges and universities aspire directly to enormous variation in their graduates. Upon choosing a major area of study, a college student starts down a path that will lead to specialized understanding that most of his or her peers will not share upon graduation. Colleges and universities provide society with a population that holds more depth and breadth of knowledge than any individual could achieve.

In the second column ${ }^{1}$ in this series we looked at the specific goal of an inhomogeneous education, dividing it into three related desires. There need to be enough people with specialized knowledge of various sorts. The knowledge must be dispersed across the population so as to allow cross-fertilization of ideas and interdisciplinary work. Third, future teachers must, as a population, have enough various kinds of specialized knowledge to improve the general state of knowledge across generations.

In general, colleges and universities reach the first of these three goals regarding the usual academic disciplines, with the possible exception of providing enough professional mathematicians, scientists and engineers. Outside of those disciplines it remains a matter of debate to what extent colleges and universities should supply the kinds of vocational training some employers desire. Higher education is very weak at the second goal, in spite of the presence of "minor" areas of study, "core requirements" and so forth. It is rare for someone majoring in engineering to have a deep understanding of anything in art or music. It is even more rare for someone majoring in music to have a deep understanding of any part of science. Achieving the second goal will require a complete rethinking of how university requirements are managed.

Of course, merely changing the requirement structure will not do the job. Departments, like individuals, are part of a system that contains explicit incentives and disincentives. Suppose a department is allocated resources according to the number of majors it has. A large population of people taking classes without an intention of majoring in the subject will change the

\footnotetext{
${ }^{1}$ "Parts of the whole: Is everything equally important?" http://dx.doi.org/10.5038/1936-4660.2.1.7.
} 
demographics of courses, without necessarily changing the resources dedicated to those courses. So, the problem of changing requirements is a systemic issue, involving different allocation of resources. If a university administrator wished to get around the resource issue, he or she could suggest providing incentives for students to take minors in those departments with lower enrollments. There are a variety of possible paths here, but all of them require bold adjustments of one kind or another.

Actual interdisciplinary study is an even harder goal to reach. It is possible to have interdisciplinary courses, yet if the student must be brought up to speed in both disciplines first, these courses will necessarily remain somewhat superficial. A carefully designed course might be able to isolate small parts of each of two disciplines and unify them in a deep way, but the more likely outcome is just an introduction to each of two separate fields.

Compounding these difficulties is the observation that it is the population that matters, not the individual. Colleges keep records of how many people major in each subject. But if we want to know about dispersion of knowledge, we need a way to measure secondary topics of study. Distribution requirements designed to enforce breadth would have to be evaluated to find out if they actually work. We would also need to know about career choices later. Merely assessing the state of knowledge dispersion in a population of graduates would be a formidable research task. To date, there is no known "sensor" of this kind of information. So, an important recommendation to the higher educational system is to clarify this second goal and design an instrument to measure it. Only then will it be possible to create good strategies for actually reaching it.

The third goal involves the education of teachers. This goal is more approachable than the last one, because prospective teachers self-identify as they go through the certification process. However, many teachers receive the bulk of their science and math education at two-year colleges, before transferring to a four-year school. In the two-year college they do not have to identify themselves as prospective teachers. In fact, some states prohibit two-year institutions from offering education courses, so these future teachers are an invisible part of the population. If future teachers are found to require deeper education in certain academic areas, such as science and math, this policy is an enormous hindrance. Any extra requirements placed upon them must be satisfied during the last two years of college. Requirements placed by the college will be fairly useless unless echoed by hiring policies and reward systems in the schools. So, once again, we see a problem whose solution is systemic in nature.

Delineating what kinds of specialized knowledge ought to be present in the population of pre-service teachers is already difficult. Organizing a strategy by which to achieve it is a systemic issue. Fortunately, it is easy to identify those who are planning to certify in a particular state, so at least it is possible to build an instrument for measuring progress along these lines. One straightforward recommendation for reaching the third goal is to require an academic major of 
every teacher. A system that allows teachers to major in education will be hard put to achieve the systemic goal of deep understanding across a variety of disciplines among teachers.

\section{Using Variation to Advantage}

It should be clear from this discussion that, at the higher levels, it is typical to encourage variation among students. It is also advantageous, as the talents and expertise needed by an entire nation cannot be embodied in a nation of very similar individuals. The goals of college are substantially different from those of the K-12 grades, and this part of the system must be managed completely differently. If variation is to proliferate, then college faculty must find ways of coping with it, both within a given class and in terms of the structure of requirements.

The fact that the purpose of higher education is to create a population full of varied, recombinant expertise does not make it any easier to deal with variation in an individual class. If a course has many prerequisites, this will guarantee a reduced variation in background knowledge among students, making it easier to teach new material. However, prerequisites simultaneously reduce the population eligible to take the course, making it more difficult to achieve the goal of placing bits of expert knowledge across a population of non-experts. In order to offer a course that goes into some depth on a topic without requiring a lot of prerequisites, one must completely rethink pedagogy. The prospect of reducing variation among students in widely ranging major fields is daunting. Instead, methods must be developed that use this variation to advantage.

The "Math Across the Curriculum Project," (MATC) at Dartmouth College, (1995-2000), was a curriculum development effort funded extensively by the National Science Foundation. One of its great success stories was a collection of courses, loosely described as "math and humanities" courses. These were forays into topics in higher mathematics, approached in an interdisciplinary fashion, and prerequisite free. Students from all different kinds of majors and backgrounds signed up to take these, and the instructors were faced with an alarmingly inhomogeneous population in their classes. Some of the suggestions in this discussion come from experience with those courses. Here we will look at ways in which the variation among students can be helpful in the classroom. In the next section we will look at ways to avoid the issue entirely.

If cognition is sometimes a process of abstracting properties from a class of examples, then diversity of viewpoint will make that process richer, if not shorter. For example, suppose the goal of a particular course is to get students to think like mathematicians. Offering a set of examples of a phenomenon and asking the students to look for common properties and themes is the first step along this path. If the class consists entirely of math majors, fairly predictable suggestions will result from such an activity. But if the class is full of people from all over the 
academic map, wide ranging suggestions will come up. This is an advantage, if we have an idea what to do with all these suggestions.

The only universal rule that applies to such a situation is this: Cherish and respect every suggestion. Any observation a student makes is a result of some thinking, and thinking is always the right first step. Beyond that one inviolable rule lie many options. Students can be asked to clarify their suggestions, whether verbally or in writing. The road to precision is arduous and most definitely an aspect of thinking like a mathematician. The students could explain why they think some observations are more promising, or interesting, than others, and the class as a whole could suggest a direction for research. The observations themselves can be classified, leading to a discussion of how a single set of examples might lead to very different branches of mathematics. Students could be asked to do some historical research to see when someone first asked a question like theirs. Some of the more clearly formulated suggestions can be tested through further examples. In all of these activities, the students are behaving exactly like research mathematicians. The breadth of background that students bring to the question leads to a rich "research program" for the class to consider.

A second advantage of a high-variation class concerns interdisciplinary work itself. If all of the students in a math and biology course (for example) are strong in math and weak in biology, it is a far less interesting course than if strength and weakness are spread around. Those strong in biology will use it as an anchor for the math. Those strong in math will connect the biology to their mathematical understanding. The cognitive pyramid ${ }^{2}$ will grow horizontally for both kinds of student, more quickly and efficiently in each other's presence. The most useful questions and observations in discussions may well come from students who are weak in both topics. Such students, if encouraged, are more likely to question the assumptions that form the basis of both mathematical models and biological dogma.

These examples represent only a few ways in which variation in student background might be used advantageously in a class. A solid body of educational research could be built around the pedagogy needed to do an optimal job in such a situation. These courses, it is only fair to say, are quite challenging to teach. The main recommendation here is that college faculty stop fighting the variation in their students by requiring many prerequisites, offering "remedial" classes, and lecturing endlessly on elementary topics. Letting go of that, we might learn to find ways of profiting from the varieties of knowledge that our students bring into the classroom.

\footnotetext{
${ }^{2}$ See "Parts of the whole: Cognition, schemas, and quantitative reasoning" http://dx.doi.org/10.5038/1936-4660.4.1.9.
} 


\section{Occasions of Zero Variation}

In spite of the potential benefits of an extremely inhomogeneous group of students, it is still true that the fastest gains in understanding are likely to be made by a room full of similarly prepared people. Even in the case of college-level subjects in a particular discipline, with no prerequisites, it is sometimes possible to achieve this blessed state. The trick is deceptively simple. One merely proposes to teach a topic so strange that nobody is likely to know anything at all about it. Complete ignorance of the entire class is, indeed, a state of zero variation.

A well-managed curriculum should include courses of this kind in every department. These courses serve a demographic not usually considered by academic departments, namely, those who define themselves as "other". This course is for someone who is not a math major. That course is for someone who is not a biology major. It is critical that courses of this kind be kept separate from the track of prerequisites to the major, otherwise they will lose their special impact on the curriculum.

An example of such a course is the "Math and Science Fiction" course taught for several years by Jody Trout and Laurence Davies at Dartmouth College. The mathematical subject material is the fourth dimension, something about which even math majors know little or nothing. Exploring the properties of a spatial fourth dimension through stories and mathematical activities yields an understanding of the kinds of thinking necessary for both math and science fiction. The subject matter is so unusual that everyone in the class starts off on the same footing. Problems of visualization plague the strong and weak math student alike. Everybody is in a position to learn a lot.

Courses with a strong historical flavor can also be designed to serve this purpose. Students may know algebra, for example, but none of them will have seen it in its original form. Students may know about the Renaissance, but few will have thought about its science or mathematics. Of course, it is critical that a course on Copernicus, for example, not be merely "about science." It must actually be science, if an understanding of science is the point, otherwise the goals stated in this essay are lost.

Parents, students and faculty ought to voice a fierce recommendation that colleges and universities make resources available for courses of the kind described here. They are, most emphatically, not "guts." Rather, they are an explicit strategy for creating a population of individuals in which small bits of specialized knowledge are dispersed widely. Learning to think in an unfamiliar discipline is a good way to learn to think, as there can be no reliance on familiar tools or memorized responses. Such courses are not the same as "introductory" courses (rocks, stars, etc.) which often have two contradictory unstated goals: convince people to major in this area of study and weed out those who are unlikely to succeed in the major. 
Few departments have internal resources to devote to developing new courses. An academic department must spend most of its resources to support its majors and the majors of related fields with requirements in that department. This is not a fault of the departments, but an outcome of the way higher education is managed. It is useless to ask departments to do otherwise, because they are part of a larger system that will not reward them for any change. The Dartmouth MATC project serves well as an example of such systemic failure. At the end of the project, departments were charged with making room for courses that were successful, at the expense of existing courses that served their majors or regular clients in other majors. A department willing to take such steps found itself working against its own best interest. Most of the new courses were discontinued within a few years.

It is also fair to point out that the first goal of higher education in general, that of making sure there are enough well-educated specialists to support the full range of needs of a nation, rests squarely on the system of specialization already used: the academic major. Some of these specialties are so small that the nation could be at risk of outsourcing key types of innovation or expertise. The goals of breadth and creative interdisciplinary thinking will not serve us, as a population, well if the specialist disappears. To echo the usual discussion of K-12 education, from where shall resources be taken? How shall requirements be framed? As always, it is a question of priorities, but priorities applied to a highly varied population rather than an individual. 